\title{
ПРОТИВОДЕЙСТВИЕ ПАТЕНТНОМУ ТРОЛЛИНГУ (НА ПРИМЕРЕ ОПЫТА США И КИТАЯ)
}

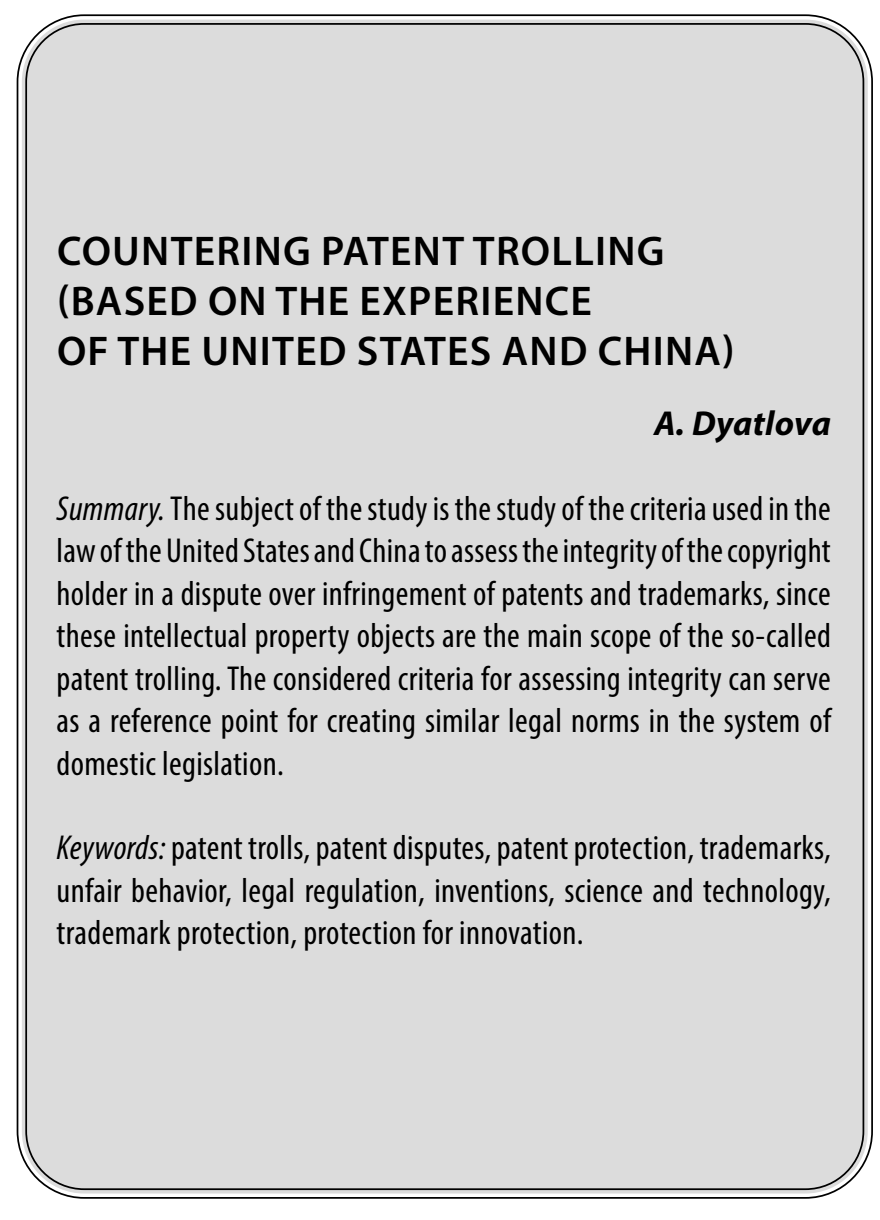

и стория патентного троллинга ведет свое начало с 1879 года, когда предприимчивому изобретателю и патентному юристу Джорджу Селдону удалось получить патент на одну из моделей бензинового автомобильного двигателя. В период активного становления отрасли машиностроения, полученный патент на многие годы обеспечил Джорджу Селдону безбедное существование за счет получения лицензионных платежей от автомобилестроителей [3].

Развитие научно-технологической сферы является благотворной почвой для патентных троллей, использующих для собственной выгоды законы о защите исключительных прав, а также общую сложность патентных споров в силу их технической составляющей.

Впоследствии в США сформировалось целое направление предпринимательской деятельности, основанное на бизнес-модели патентного троллинга.

\author{
Дятлова Алёна Владимировна \\ Всероссийский государственный университет \\ юстиции РПА Минюста России, г. Москва \\ 89161328324@mail.ru
}

Аннотация. Предметом исследования является изучение применяемых в праве США и Китая критериев оценки добросовестности правообладателя в споре 0 нарушении прав на патенты и товарные знаки, поскольку данные объекты интеллектуальной собственности являются основной сферой действия так называемого патентного троллинга. Рассмотренные критерии оценки добросовестности могут служить в качестве ориентира для создания аналогичных правовых норм в системе отечественного законодательства.

Ключевые слова: патентные тролли, патентные споры, патентная защита, товарные знаки, недобросовестное поведение, правовое регулирование, изобретения, научно-технологическое развитие, защита товарных знаков, защита инноваций.

В своевременных реалиях патентный троллинг развит в сферах компьютерных технологий, электроники, программного обеспечения, биотехнологий и фарминдустрии.

Помимо этого, существует патентный троллинг в сфере товарных знаков.

K негативным проявлениям патентного троллинга можно отнести: замедление производственного и инновационного развития, в частности, в силу усложнения доступа к использованию определенных технологий; снижение экономического роста компаний, вынужденных тратить значительные средства на судебные тяжбы и лицензионные выплаты патентным троллям.

Так, в соответствии с исследованием, проведенном в 2018 году Гарвардским университетом и университетом Техаса, было выявлено, что большинство компаний, 
проигравших в споре с патентными троллями, были вынуждены свернуть свои научно-исследовательские проекты в силу невозможности их дальнейшего субсидирования [7].

Патентный троллинг может явиться причиной повышения цен на определенную продукцию, поскольку, суммы лицензионных отчислений влияют на их конечную стоимость и приводят к удорожанию.

Наибольшее негативное воздействие от патентного троллинга претерпевает малый бизнес, которому в силу ограниченности финансовых возможностей, гораздо сложнее обеспечить себе должную юридическую защиту, нежели чем крупной компании.

Поскольку продвижение научно-технологического прогресса является одной из основных целей развития России, представляется актуальным исследовать установленные законодательной и правоприменительной практикой США и Китая критерии оценки недобросовестности правообладателя, позволяющие, в свою очередь, осуществить противодействие патентному троллингу как одной из угроз не только для научно-технологического, но и для экономического развития государства.

В качестве патентного троллинга учеными рассматривается деятельность в сфере исключительных прав, которая заключается не в разработке и производстве новой продукции или создании новых объектов исключительных прав, а в систематическом использовании таких прав исключительно с целью злоупотребления реализацией субъективного права на защиту или получения лицензионных отчислений [5].

В общем виде, структура действия патентного троллинга практически идентична осуществлению защиты нарушенных прав добросовестного правообладателя. Поэтому, запретить данное явление на законодательном уровне не представляется возможным.

Стратегия успеха патентного троллинга базируется на серьезности как материальных, так и правовых последствий за нарушение исключительных прав. Патентные тролли, принуждают оппонентов пойти на их условия, дабы избежать неблагоприятного исхода в случае поражения в суде.

Американские ученые склонные связывать определение патентного троллинга с деятельность так называемых компаний - «непрактикующих патентнообладетей» - Patent assertion entities (PAE).

Целью деятельности данных компаний является получение лицензионных платежей за счет использо- вания принадлежащих им патентов, без попыток реализовать запатентованные изобретения на практике. Как правило, это небольшие компании, которые за счет предъявления патентных судебных исков пытаются вынудить как можно больше компаний приобрести лицензии на их патенты [3].

Говоря о сложности при рассмотрении патентных споров, следует обратиться к мнению ученых-юристов А.Г. Барабашева и Д.В. Пономаревой, согласно которому, порой представляется затруднительным определить точную границу между множеством запатентованных технологий, используемых в определенном устройстве.

Если прибавить к этому, особенности формулировок патентуемых технологий, некоторые из которых носят размытый характер, то становится очевидно, что доказать свою правоту в споре с патентным троллем не всегда представляется возможным [2].

В качестве мер по снижению распространения патентного троллинга, законами ряда американских штатов были установлены следующие критерии недобросовестности правообладателя в споре о нарушении патентных прав:

1. Требования заявителя не содержит номера и наименования патента; информацию о владельце патента, а также доказательства нарушения исключительного права на патент;

2. Требования заявителя были направлены без проведения проверки использования патента в оспариваемом продукте или технологии;

3. Установлен короткий период для заключения лицензионного договора и выплат роялти;

4. Требование о размере лицензионных платежей значительно превышают стоимость самого патента;

5. Лицо, направившее требование заведомо знало о необоснованности своих претензий;

6. Иные факторы, которые суд сочтет показателями недобросовестности правообладателя. [6, с. 55]

Направление подобных требований, признается в ряде штатов правонарушением, что, в свою очередь, предписывает прокурору штата провести расследования и привлечь виновных к ответственности. В качестве санкции за данное деяние установлен штраф, размер которого устанавливается законом штата.

Помимо этого, некоторые штаты допускают для получателей «писем-требований» возможность самостоятельно взыскать с патентного тролля убытки, причиненные его действиями [13].

Схема действия патентного троллинга в сфере товарных знаков заключается в том, что права на товар- 
ные знаки, имеющие схожие черты с теми, которые используются добросовестными правообладателями, служат в качестве средства для инициирования судебных процессов с целью получения компенсации за нарушение прав на товарный знак.

В данном случае, товарные знаки приобретаются или регистрируются патентным троллем не для того чтобы использовать их в предпринимательской деятельности, а только в качестве предмета судебных тяжб.

В части рассмотрения критериев недобросовестности в части троллинга в сфере товарных знаков, следует обратиться к опыту Китая, где данное явление стало насущной проблемой, когда выяснилось, что в Китае зарегистрировано множество товарных знаков, схожих с такими известными международными брендами как Adidas, Tesla, Apple и другие.

В данном случае приоритетность товарного знака играет на пользу патентным троллям, поскольку они регистрируют похожий товарный знак до того, как «оригинальный товарный знак» выйдет на китайский рынок.

С данным негативным явлением с свое время столкнулись компании Apple и Tesla. Проиграв судебные споры с патентными троллями, они вынуждены были пойти на их условия и выплатить компенсацию.

В рамках принятия мер для противодействия данному явлению, в 2019 году в законодательства Китая о товарных знаках были внесены изменения, призванные снизить количество товарных знаков, зарегистрированных с недобросовестными намерениями.

Так, согласно закону, заявки на товарные знаки, поданные без цели дальнейшего использования товарного знака по назначению, в частности, для представления товаров и услуг, должны быть отклонены [15].

Для проверки добросовестности заявителя, регистрационные органы руководствуются рядом критериев, среди которых можно выделить следующие:

1. Общее количество заявок, поданных заявителем и аффинированными лицами.

2. История транзакций товарных знаков. В данном случае эксперты выясняют, историю использования товарных знаков, уже зарегистрированных заявителем.

3. Общее количество судебных дел в отношении заявителя и аффинированных лиц по основаниям «недобросовестности».

По данным исследователей, данные меры показали свою эффективность в части увеличения количества от- казов в регистрации «недобросовестных» заявок на товарные знаки [13].

Проведение подобных проверок «недобросовестности заявителей» представляется эффективным средством для борьбы с троллингом в сфере товарных знаков, поскольку снижение вероятности регистрации «недобросовестного» товарного знака, затрудняет возможность осуществления дальнейшей деятельности «тролля» в данной сфере.

В судебной практике Китая также был установлен перечень критериев, свидетельствующих о «недобросовестности» правообладателя в споре о нарушении прав на товарные знаки.

Перечень данных критериев был обозначен Верховным судом Китая в споре в отношении товарного знака между китайскими предпринимателями и японской компанией “Uniqlo".

Так, несколькими китайскими предпринимателями был зарегистрирован товарный знак "UL", идентичный товарному знаку, который "Uniqlo" уже использует по всему миру.

B дальнейшем, когда компания «Uniqlo» вышла на китайский рынок, она столкнулась с троллингом.

Рассматривая данное дело, Верховный суд Китая определил следующие критерии недобросовестности правообладателей:

1. Множественность зарегистрированных товарных знаков. В рассматриваемом деле их более 2600;

2. Товарные знаки не использовались по назначению, то есть, для продвижения товаров и/или оказания услуг;

3. Ответчику предлагалось выкупить товарный знак по завышенной стоимости;

4. Судебные разбирательства в отношении ответчика инициировались с целью принудить его согласиться на условия истца.

Таким образом, «Uniqlo» не только удалось отстоять свою правоту в данном деле, но и создать судебный прецедент, согласно которому, «недобросовестные действия» правообладателей товарных знаков могут служить основанием для отказа в удовлетворении их требований [14].

Открытым остается вопрос, возможно ли рассмотреть в качестве патентного тролля лицо или организацию, если патентный троллинг не является их основным видом деятельности. 
Так, в качестве примера можно привести деятельность американской компании Intellectual Ventures имеющей права на более чем 40 тысяч патентов в 50 технологических сферах.

Помимо деятельности, которою можно отнести к патентному троллингу, Intellectual Ventures имеет собственные лаборатории и штат ученых, осуществляющих научную и изобретательскую деятельность.

В общем понимании, такие компании как Intellectual Ventures отошли от классического понимания компаний-троллей,, поскольку помимо прочего, они осуществляют деятельность по развитию науки и технологий.

Отвечая на вопрос, можно ли рассматривать подобные компании в качестве «патентных троллей», следует обратиться к определению патентного троллинга.

Согласно определению, «патентный троллинг» рассматривается в качестве «определенной деятельности» организаций или физических лиц.

Можно предположить, что деятельность по патентному троллингу не исключает ведения иной добросовестной научно-технологической или производственной деятельности.

Вместе с тем, в виду затруднительности применения рассматриваемых критериев ко всем правоотношениям в части как патентных споров, так и споров в сфере товарных знаков, представляется верным, применять рассмотренные критерии к организациям и физическим лицам, деятельность которых отвечает следующим признакам:

1. Множественность споров по данному основанию;

2. Отсутствие использования патентов или товарных знаков по назначению, для ведения научно-технологической или производственной деятельности.

3. Использование прав на патенты и товарные знаки для инициирования судебных процессов с целью получения материальной выгоды, что можно увидеть исходя из требования завышенных сумм для лицензионных платежей или выкупа патента/ товарного знака.

4. Мотивацией правообладателя для судебного разбирательства служит возможность воспрепятствовать предпринимательской деятельности ответчика, в целях принудить его пойти на сделку.

Рассмотренные критерии оценки могут способствовать систематизации в применении принципа добросовестности в части противодействия патентному троллингу и троллингу в сфере товарных знаков, а также служить ориентиром для законопослушного поведения участников гражданского оборота.

Зарубежная практика по борьбе с патентным троллингом, в частности, введение критериев оценки недобросовестности может служить образцом для создания аналогичных норм в рамках российского права.

\section{ЛИТЕРАТУРА}

1. Афанасьева Е.Г. Тролли водятся в Америке. А в Европе? (Аналитический обзор) / Е.Г. Афанасьева, Е.А. Афанасьева. - Текст: непосредственный // Право интеллектуальной собственности: Сб. науч. тр. / РАН. ИНИОН. Центр социал. науч.-информ. исслед. Отд. правоведения; МГУ им. М.В. Ломоносова. Каф. предпринимательского права.— 2017. — № . - С. 66-72.

2. Барабашев А.Г., Пономарева Д.В. Патентный троллинг и правовое регулирование искусственного интеллекта (на примере опыта Соединенных Штатов Америки) / А.Г. Барабашев, Д.В. Пономарева.— Текст: непосредственный // 0бразование. Наука. Научные кадры.— 2021.— № 1.—C. 41-48.

3. Васильев Д.В. Патентный троллинг: зарубежный опыт и правоприменительная практика в России / Д.В. Васильев. - Текст: непосредственный // 06разование. Наука. Научные кадры.— 2019.— № 4.—C. 97-101.

4. Ворожевич, А.С. Патентный троллинг: сущность, история, правовые механизмы борьбы / А.С. Ворожевич. — Текст: непосредственный // Закон. 2013.— № 9.—C. http://base.garant.ru/57597235/.

5. Николаев К.А. Правовые средства пресечения патентного троллинга и возможности применения законодательства о защите конкуренции//Предпринимательское право.2019 № 1 с. 60-66

6. Седнев. В.А. Патентный троллинг: понятие, механизмы борьбы / В.А. Седнев. - Текст: непосредственный // Журнал Суда по интеллектуальным правам. - 2020.- № 4.- C. 25-31.

7. Юнисов, Р.Р. Правовые вопросы деятельности патентных троллей / Р.Р. Юнисов. - Текст: непосредственный // Теории, школы и концепции устойчивого развития науки в современных условиях Сборник статей по итогам Международной научно-практической конференции 28 марта 2020 г. 2020.—№ .—C. 104-107.

8. Bessen, J. The Evidence Is In: Patent Trolls Do Hurt Innovation / J. Bessen. — Текст: электронный // Harvard Business Review: [cайт].— URL: https://hbr. org/2014/07/the-evidence-is-in-patent-trolls-do-hurt-innovation (дата обращения: 09.05.2021). 
9. Boyle, A. Inside the invention factory: Get a peek at Intellectual Ventures' lab / A. Boyle.— - Текст: электронный // GeekWire: [caйт]. — URL: https://www. geekwire.com/2016/inside-intellectual-ventures-lab/ (дата обращения: 10.05.2021).

10. Huang, Q. Navigating the landscape of anti-trolling legislation / Q. Huang, G. King, T. Rawson. - Текст: непосредственный // Intellectual Property Magazine. - 2016. - № 6. - P. 54-56.

11. Luna, A.C. China: Fighting Trademark Trolls / A.C. Luna.— —екст: непосредственный // Fross Zelnick Lehrman \& Zissu, PC.— 2021.— № . [сайт].URL: https:// www.mondaq.com/china/trademark/1047766/fighting-trademark-trolls.

12. Plumley, D.A. Don't Feed the Patent Trolls / D.A. Plumley.— Текст: электронный // Lewis Roca: [сайт].— URL: https://www.lewisroca.com/blog/dont-feedthe-patent-trolls (дата обращения: 09.05.2021).

13. Swain, P. Patent Troll Watch — States Are Pushing Patent Trolls Away from the Legal Line / P. Swain. — Текст: электронный // The JD Supra Knowledge Center: [сайт].—URL: https://www.jdsupra.com/legalnews/patent-troll-watch-states-are-pushing-71479/ (дата обращения: 09.05.2021).

14. Xu A., Chan V. How China is acting to combat bad faith trademarks / A. Хu. — Текст: электронный // Managing IP: [caйт]. — URL: https://www.managingip. com/article/b1rczznxf2q8kf/how-china-is-acting-to-combat-bad-faith-trademarks (дата обращения: 11.05.2021).

15. Zhang, Z. China's New Trademark Law in Effect from November 1 / Z. Zhang. - Текст: электронный // China Briefing: [сайт]. — URL: https://www.chinabriefing.com/news/chinas-new-trademark-law-effect-november-1-2019/ (дата обращения: 09.05.2021).

16. A Crushing Defeat for Trademark Trolls. — Текст: электронный // Dechert LLP: [сайт].— URL: https://www.dechert.com/knowledge/onpoint/2019/8/acrushing-defeat-for-trademark-trolls.html (дата обращения: 09.05.2021).

17. China's Trademark Law Amendments Tighten Restrictions on Bad-Faith Filing. — Текст: электронный // International Trademark Association: [caйт].— URL: https://www.inta.org/chinas-trademark-law-amendments-tighten-restrictions-on-bad-faith-filing/ (дата обращения: 11.05.2021).

18. Intellectual Ventures Signs Patent License Agreement with Infineon Technologies. — Текст: электронный // Intellectual Ventures: [cайт]. — URL: https://www. intellectualventures.com/buzz/press-releases/intellectual-ventures-signs-patent-license-agreement-with-infineon-technolo (дата 0бращения: 11.05.2021).

( Дятлова Алёна Владимировна ( 89161328324@mail.ru ).

Журнал «Современная наука: актуальные проблемы теории и практики»

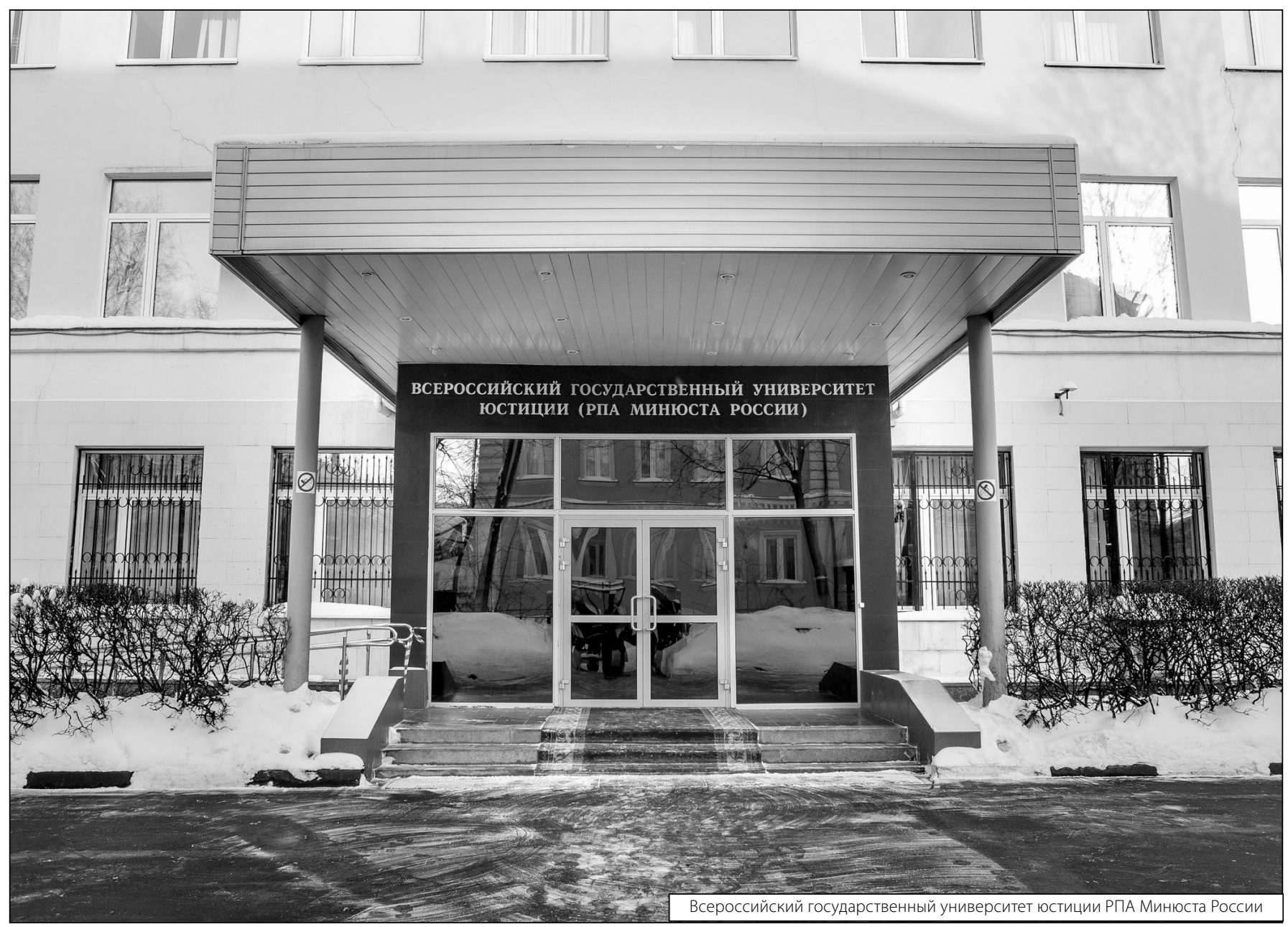

